\title{
Fahr's Disease with Oral Manifestations: Report of a Rare Case
}

\author{
Amita Aditya $^{a}$ Shailesh Lele ${ }^{a}$ Priyam Aditya $^{b}$ \\ Departments of a Oral Medicine and Radiology and ${ }^{b}$ Prosthodontics, Sinhgad Dental College and Hospital, Pune, India
}

\author{
Key Words \\ Fahr's disease $\cdot$ Calcification · Basal ganglia
}

\begin{abstract}
Objective: The purpose of this article is to discuss the general and oral findings in a patient with Fahr's disease, an uncommon disorder. Clinical Presentation and Intervention: A patient presented with the complaint of partial anodontia, but further clinical and radiographic investigations showed a myriad of findings including stunted growth, osteoporosis and pathological calcifications. Oral findings included oligodontia and advanced periodontitis in relation to the present teeth. Full-mouth rehabilitation was eventually planned for the patient. Conclusion: This case shows the necessity for dentists to be aware of symptoms associated with Fahr's syndrome in order to make appropriate referrals and to enable diagnosis and treatment.

Copyright $\odot 2012$ S. Karger AG, Basel
\end{abstract}

\section{Introduction}

Fahr's disease, Fahr's syndrome or striopallidodentate calcinosis are all pathological terms for the idiopathic nonarteriosclerotic cerebral calcification of the striopallidodentate system. The syndrome, which is either familial or sporadic, shows a wide range of clinical signs with progressive mental deterioration of pyramidal, extra-pyramidal and cerebellar signs $[1,2]$. Very little information is available regarding the nonneurological manifestations of this disease, and almost no information is available on the oral findings. Considering the various metabolic abnormalities such as stunted physical and neuropsychological development in these patients, one could expect abnormalities in the oral tissues as well. Hence, we report a case of Fahr's disease with oral manifestations.

\section{Case Report}

A 23-year old woman, accompanied by her mother, reported to our department with partial anodontia, but no eruption of some of the permanent teeth. They were not able to provide a complete dental history, but from the prenatal and antenatal history obtained from the mother, there had been no maternal infection during pregnancy nor any abnormalities, other than short toes and fingers since birth and a delayed achievement of milestones like standing, walking and speech. The patient had apparently had normal growth until the age of 4-5 years, after which her growth was stunted. She did attain menarche at the normal age, but complained of oligomenorrhea. She also had a history of episodes of seizures since the age of about 10 years. Her mother also reported a gradual development of motor incoordination and diminished vision. The family history revealed secondary consanguineous marriage; however, no other sibling had similar complaints. A history of any other infection during childhood was also denied by the parent.

The patient appeared to be a little disoriented, short of stature (height $=125 \mathrm{~cm}$, weight $=34 \mathrm{~kg}$ ) with abnormally short digits (fig. 1). Physical examination revealed several hypopigmented to depigmented macules on the face. Multiple, slightly hyperpigmented plaques were seen on the abdomen, right arm, left thigh and leg and right calf. Multiple small, hard papules were also seen on the extremities, especially on the flexor surface.

\section{KARGER}

Fax +41613061234

E-Mail karger@karger.ch

www.karger.com
(C) 2012 S. Karger AG, Basel

$1011-7571 / 12 / 0214-0395 \$ 38.00 / 0$

Accessible online at:

www.karger.com/mpp
Amita Aditya

Department of Oral Medicine and Radiology, Sinhgad Dental College and Hospital

S. no. 44/1, Vadgaon (Bk), Off Sinhgad Road

Pune 411041 (India)

Tel. +91976 400 3901, E-Mail dr.amita30@ rediffmail.com 

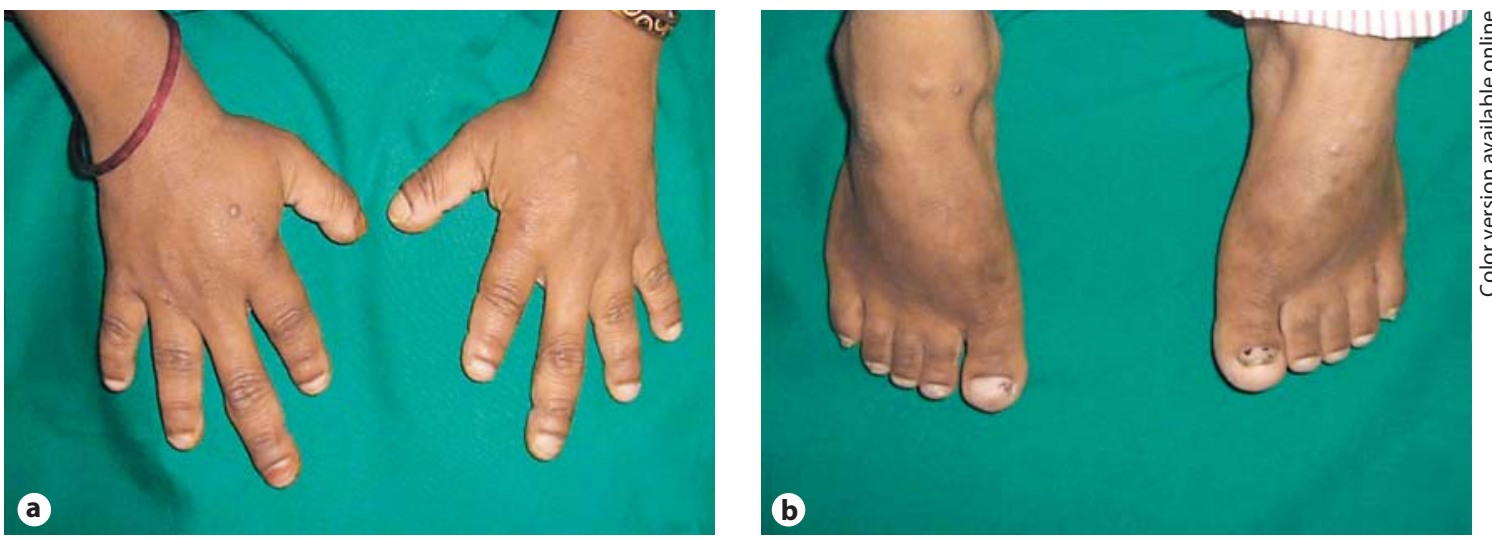

Fig. 1. Short, deformed digits of hands (a) and feet (b). Note the claw-like appearance of the hands and the papular lesions on the skin.

Oral examination revealed oligodontia with missing maxillary central incisors, maxillary right premolars and second molar, mandibular left second premolar and molars, and mandibular right lateral incisors, canine, premolars as well as molars. Mobility was present with the remaining teeth. Generalized gingival inflammation and recession was also evident.

A thorough radiographic examination was carried out. Panoramic radiograph revealed partial anodontia, as well as partially developed maxillary and mandibular second molars and mandibular left second premolar. The mandibular right canine was impacted. Development of the roots of the present teeth appeared to be stunted along with moderate horizontal bone loss. An interesting finding was the generalized rarefaction of the bone, simulating that in hypoparathyroidism (fig. 2). Hand-wrist radiograph revealed osteoporosis with cupping deformity at articular surfaces.

Based on the clinical findings, a provisional diagnosis of hypoparathyroidism was made. Blood investigations revealed highserum phosphorus $(6.88 \mathrm{mg} / \mathrm{dl})$, slightly high-serum alkaline phosphatase (124 IU/l), and slightly low-serum calcium $(8.23 \mathrm{mg} /$ dl) levels. The serum lactate dehydrogenase level was very high (1,083 IU/l). Thyroid stimulating hormone and parathyroid hormone levels were also very high, being $8.21 \mu \mathrm{IU} / \mathrm{ml}$ and $878.50 \mathrm{pg} /$ $\mathrm{ml}$ respectively.

Considering the episodes of seizures experienced by the patient, computed tomography of the brain was also conducted which revealed calcifications in the bilateral caudate nucleus, putamen, globus pallidus, thalamus, basal ganglia, cerebral hemispheres and cortical white matter (fig. 3). Calcific densities were also seen in the scalp. The above features were highly suggestive of Fahr's disease. The possibility of hypoparathyroidism was less likely, as the cerebellum also showed calcifications. In hypoparathyroidism, calcifications may also occur, but they are limited to the basal ganglia.

Based on the physical, clinical and imaging features, a diagnosis of Fahr's disease was made. Considering the gravity of the neuronal and general findings, the patient was referred to the Departments of Neurosurgery and General Medicine for further evaluation and management before any dental treatment was performed.

In further follow-up visits, reports were acquired from the Departments of Medicine and Psychiatry that showed certain neuropsychological symptoms in the patient. Neurological examination revealed subnormal consciousness and orientation. The left

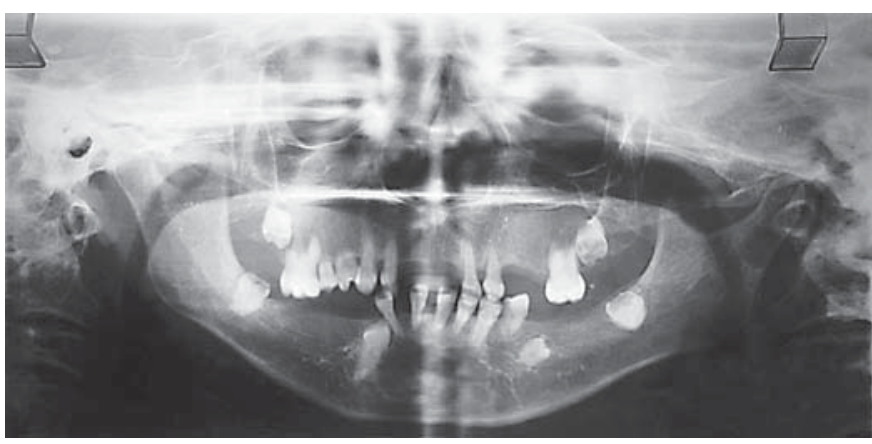

Fig. 2. Panoramic radiograph showing generalized rarefaction of the jaw bone.

eye was not found to have any light perception; however, vision in the right eye appeared to be normal. For psychological assessment, a verbal intelligence test was carried out that revealed understanding, attention span and body and time orientation at the level of a 4-year-old. The Indian adaptation of the Vineland Social Maturity Scale, which is used for the quantification of social maturity in terms of social age and social quotient, revealed a the level of a 5-year-old, indicative of severe mental retardation. Psychiatric assessment did not reveal any behavioral disturbances; however, a direct interview with the patient did reveal sadness of mood and minor depression.

At the last contact, the patient had undergone eye surgery for bilateral cataracts. For dental management, full mouth rehabilitation is currently being planned for the patient.

\section{Discussion}

Fahr's syndrome is actually a diagnosis of exclusion since there are several other conditions that have been associated with calcification of the basal ganglia. These include physiological causes like senility and pathological 

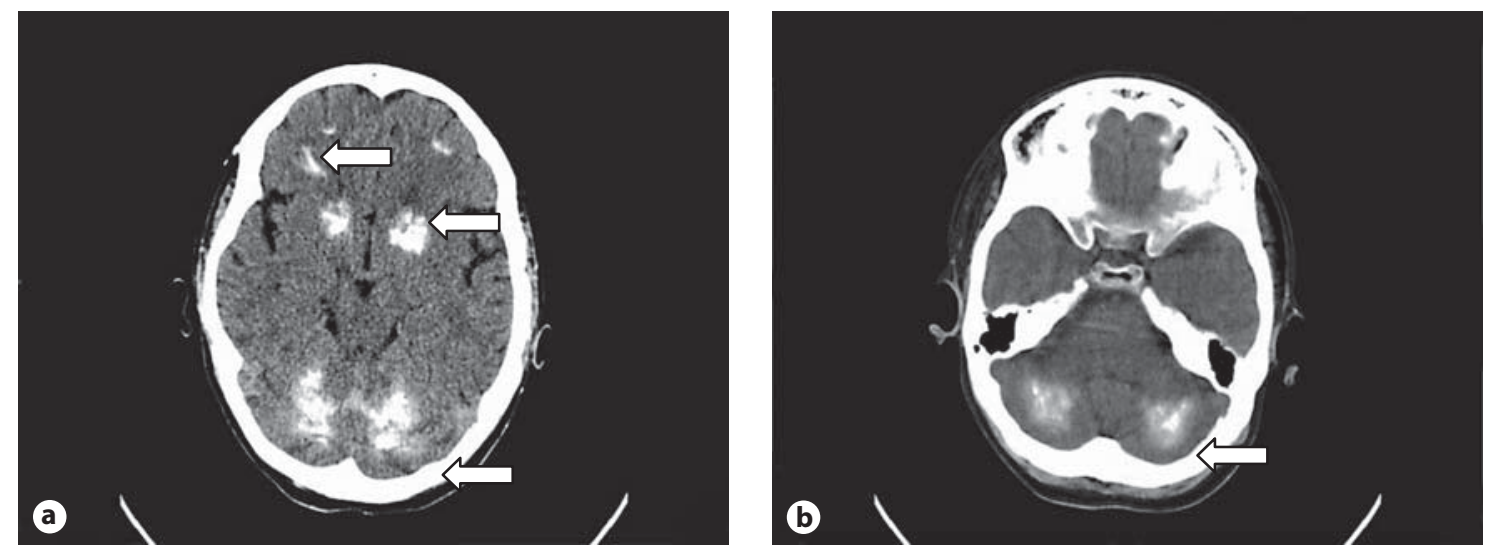

Fig. 3. Computed tomography images showing calcifications in different regions of the brain (marked with arrows).

causes like hypoparathyroidism, carbon monoxide intoxication, tuberous sclerosis and toxoplasmosis. These factors should first be ruled out in order to diagnose Fahr's disease. In our case, the imaging findings as well as the presence of all the other characteristic symptoms associated with Fahr's syndrome helped to establish the diagnosis.

Due to the coexistence of various metabolic and neurological abnormalities, it is difficult to assess neurological deficits as the cause or consequence of Fahr's syndrome. Many findings associated with Fahr's syndrome appear to be overlapping with hypoparathyroidism. This could be attributed to the possibility of the concomitant presence of hypoparathyroidism in patients suffering from this disorder [3]. The metabolic changes, especially those associated with aberrancy in calcium metabolism, may lead to abnormalities of the teeth and bone structure. Rarefaction of bone and poor development of teeth due to these metabolic changes can be expected. To date, however, changes in oral tissues have not been adequately documented (as it was in this case).

Fahr's disease is associated with abnormal calcium deposits in the basal ganglia, primarily in the globus pallidus region and often in other parts of the brain. Clinical features are important because basal ganglia calcification may be viewed as an incidental finding. Headache, vertigo, movement disorders, paresis, stroke-like events, cognitive impairment, psychiatric disorders, pyramidal signals and seizures are the most common manifestations [4]. In addition, it has been stated that 'pathological calcifications' exist when regions other than the globus pallidus are involved [5]. Malfunctioning parathyroid glands and low blood calcium levels are also observed. The disease may also cause a variety of physical and psy- chological symptoms. Muscle stiffness, movement disorders and paralysis may occur. In some cases, Fahr's disease is also associated with vision problems and ear infections [6-8]. Our patient showed all the above-mentioned symptoms. Ours is probably the first case report regarding the oral changes in Fahr's syndrome.

\section{Conclusion}

This case showed the necessity for dentists to be aware of symptoms associated with Fahr's syndrome in order to make appropriate referrals and to enable diagnosis and treatment.

\section{References}

1 Chalkias SM, Magnaldi S, Cova MA, Longo R, Pozzi-Muccui RS: Fahr disease: significance and predictive value of CT and MRI findings. Eur Radiol 1992;2:570-575.

-2 Khammabi M, Christi J, Mohsen D, Abdelhedi H, Tougorti MN, Hamza M: Fahr's syndrome: two case reports. Rev Neurol 2010;166:446-450.

3 Basak R: A case report of basal ganglia calcification - a rare finding of hypoparathyroidism. OMJ 2009;24:220-222.

4 Levy G: Basal ganglia calcification (striopallidodentate calcification) and cognitive impairment. Arq Neuropsiquiatr 1999;57:148.

5 Harrington MG, Macpherson P, Mcintosh WB, Allam BF, Boné I: The significance of the incidental finding of basal ganglia calcification on computed tomography. J Neurol Neurosurg Psychiatry 1981;44:11681170 .

6 Geschwind DH, Loginov M, Stern JM: Identification of a locus on chromosome 14q for idiopathic basal ganglia calcification (Fahr's disease). Am J Hum Genet 1999;65:764-772.

7 Sharma OP, Sentil S, Sharma G: Fahr's syndrome: report of two cases. J Indian Med Assoc 2010;108:776-777.

8 Bourgeois IA: Fahr's Disease - a model of neuropsychiatrc illness with cognitive and psychiatric symptoms. Acta Psychiatr Scand 2010;121:78. 